\title{
Needlescopic Reduction and Inversion Snaring of Hernia Sac for the Treatment of Ovarian Hernia; A Case Report
}

\author{
Rafik Shalaby'*, Soliman Mohamad', Mohamed Ahmed Negm², Hanaa El-Ebesy ${ }^{3}$ \\ 'Department of Pediatric Surgery, Al-Azhar University, Cairo, Egypt \\ ${ }^{2}$ Pediatric Surgery Unit, Qena University Hospital, South Valley University, Qena, Egypt \\ ${ }^{3}$ Obstetrics and Gynecology Departments, Al-Azhar University, Cairo, Egypt
}

*Address for Correspondence: Rafik Shalaby, Department of Pediatric Surgery, Al-Azhar University, Cairo, Egypt. E mail: rafikshalaby40@gmail.com

Received: 15 May 2020; Accepted: 26 June 2020; Published: 29 June 2020

Citation of this article: Shalaby R, Mohamad S, Negm MA, El-Ebesy H (2020) Needlescopic Reduction and Inversion Snaring of Hernia Sac for the Treatment of Ovarian Hernia; A Case Report. Rea Int Journal of Clin med Case Rep. 1(1): 001-004. DOI: $10.37179 /$ rijcmcr.000001.

Copyright: (C) 2020 Shalaby R. This is an open access article distributed under the Creative Commons Attribution License, which permits unrestricted use, distribution, and reproduction in any medium, provided the original work is properly cited.

\begin{abstract}
Inguinal hernia repair is one on the most frequently performed operative procedures in paediatric surgery. Several laparoscopic techniques have been described Ovarian hernia is defined as the ovarian herniation into the inguinal hernia sac.

This case report described a case of ovarian hernia in a 6-months girl. The hernia sac contents were reduced, and the sac was closed by a new technique of inversion and snaring of hernial sac. In this technique the sac was grasped, inverted then snared using "Acusnare polypectomy snare" This technique is simple, reproducible and can be performed quickly.
\end{abstract}

Keywords: Ovarian Hernia, Needlescopy, Incarcerated Inguinal Hernia in Girl

\section{Introduction}

In girls, the incidence of inguinal hernia is more than four times lower than in boys, however the incidence of bilateral inguinal hernias is almost twice as high as in boys (25.4\% vs $12.9 \%)$ [1] Sliding indirect inguinal hernias containing the ovary and Fallopian tube is not uncommon in younger girls. Reproductive organs (most commonly ovary) are content of the hernia sac in girls in $15-31 \%$ [2].

Although an irreducible ovary is not at great risk of incarceration, this condition may become a significant risk factor for torsion or strangulation [2-4].

Ovarian hernia is defined as herniation of the ovary into the inguinal hernia sac. It is reported that $15 \%-20 \%$ of all canal of Nuck hernias containing ovaries and on some occasion with its Fallopian tube [5]. In these cases, ovarian torsions have been reported in $2 \%-33 \%$, emphasizing the importance of early surgical repair in irreducible hernias, even in asymptomatic patients.
Gaspar et al. [6] defined sliding hernia as "Sliding hernias are those in which part of the wall of the sac is formed by a viscus." Cases of ovarian hernia in which the ovary can easily be reduced are not included in the definition of "ovarian sliding hernia."

Herein we describe a case of incarcerated ovarian hernia that was managed for the first time by applying a new technique which is "needlescopic reduction of incarcerated ovary and tubes with inversion and snaring of the hernia sac".

\section{Case Report}

A 6-month old girl presented to out-patient clinic with left inguinal swelling. The mother reported that she noticed a swelling in the left groin area since birth which appears on crying and disappears on sleeping. But recently she noticed that the swelling is present all the time and does not disappear. On clinical examination the girl was generally well-nourished and calm without any history of vomiting or absolute constipation. There was a left inguinal hernia with palpable ovary which was irreducible. 
Blood counts and biochemical values were within normal limits. Inguinoscrotal U/S suggested left congenital hernia with the possibility of incarcerated ovary and Fallopian tube. After assigned detailed informed consent by the parents, the case was scheduled for needlescopic hernia repair. Intra-operatively there was left ovarian hernia where both ovary and Fallopian tube was incarcerated into the hernial sac. For the first time, 2 Suture grasper device 1.4-Gauge were used for reduction the hernia content and inversion and snaring the hernia sac safely.

\section{Operative Technique:}

Under general anaesthesia with Trendelenburg's position, insertion of the main umbilical port was accomplished by the open method. Pneumoperitoneum was established to a pressure of $8 \mathrm{~mm}$ $\mathrm{Hg}$. and a $5-\mathrm{mm} 30^{\circ}$ telescope was inserted in the umbilical port. Two suture grasper devices (SGDS), for working instruments, were inserted at the midclavicular line at the level of the umbilicus.

Needlescopic reduction of both ovary and Fallopian`s tube was done then the hernia sac inversion was done as described by Shalaby and Negm [7] with some modification in the form of using 2 suture grasper devices and Acusnare polypectomy snare [Cook Medical, Wilson-cook Medical, Inc.4900 Bethania Road Winston-Salem NC27105.WWW.cookmedical.com]" and 2 Suture Grasper Devices.

The snare was introduced into the ovary and its Fallopian tube was gently reduced by alternate traction movement by the two SGDS on the round ligament (Figure 1). The abdominal cavity at the site of right suture grasper device. The ipsilateral SGD was passed into the opened loop of the Snare and the hernia sac was re-grasped again and twisted (Figure 2). So, the inverted, twisted hernia sac was snared and cauterized slowly with low monopolar cutting diathermy at the neck of the hernia sac in interrupted manner Figure 2. The twisted snared distal sac was extracted, through the umbilical port with the aid of SGDs and peritoneal defect was closed with polypropylene suture.

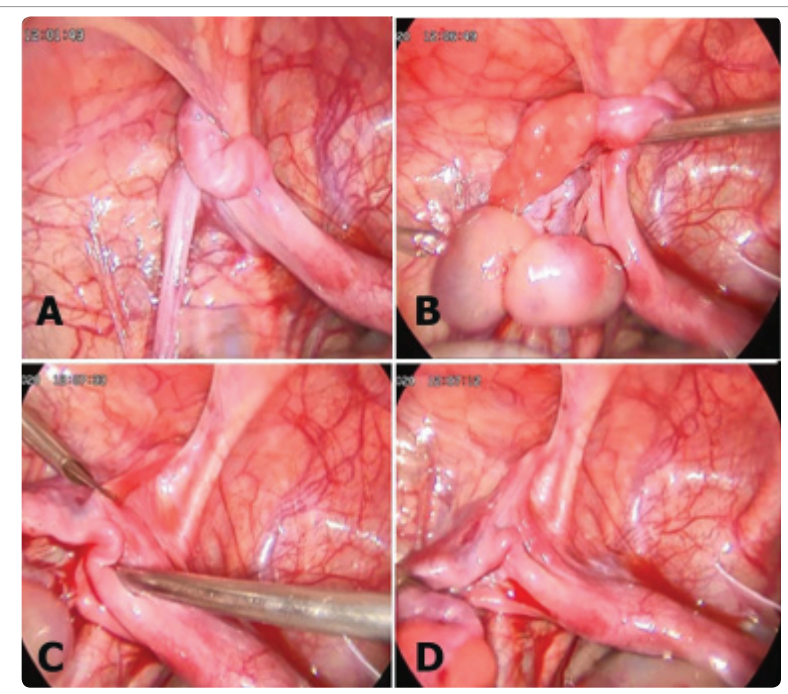

Figure 1: Incarcerated ovary and Fallopian tube in a left sided inguinal hernia

A) The ovary and its Fallopian tube seen incarcerated inside the canal of Nuck

B) Reduction of the ovary and appearance of fimbrian end of the tube

C) Complete reduction by the SGD

D) Appearance of short round ligament

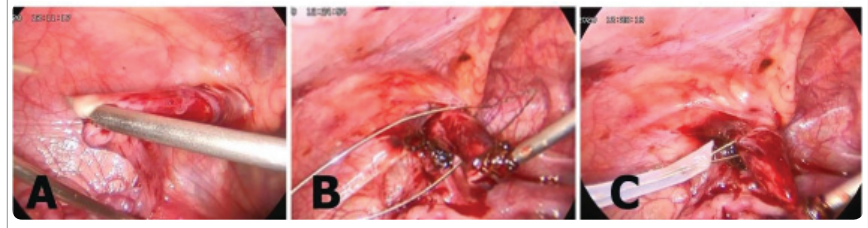

Figure 2: Inversion and snaring of the hernia sac

A) inversion of the sac by SGD

B) Application of the snare

C) Closure of the snare to encircle the sac at its neck.

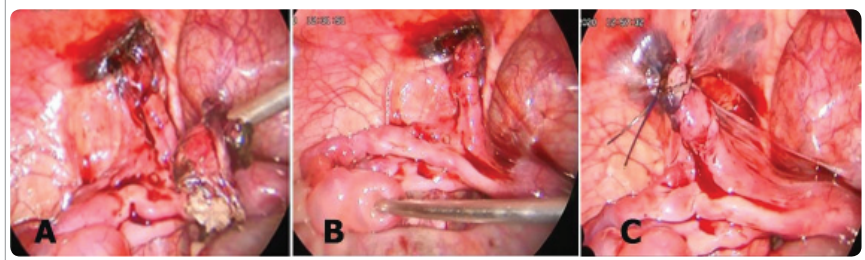

Figure 3: Separation and peritoneal closure

A)The sac now separated after application of low current cutting mode diathermy

B) The peritoneal defect

C) Peritoneal closure and the end of surgery.

(Figure 3). https://drive.google.com/open?id=1Ay9VBKYJM0SJP m9sekzvjgfCOC9LBxtM. Recovery was quick and uneventful and patient was discharged in the evening of the same day.

\section{Discussion}

It is reported that the ovary is herniated in $15 \%-20 \%$ of female patients with inguinal hernia. [5]. Ovarian hernia is more frequently seen in infants than in older girls and early or emergency surgical repair is female recommended because of the risk of ovarian torsion. Our case presented with ovarian hernia in a 6-month girl and the incidence coincides with others $[8,9]$.

Laparoscopy for inguinal hernia was firstly done in girls by ElGohary in1997 [10], since then, many laparoscopic techniques for inguinal hernia repair was developed aiming for achieving the advantage of minimal invasive surgery and decreasing the rate of recurrence [10-12]. This operation initially carried out in female because it is safer than males due to absence of vas and testicular vessels [10] Takehara et al. reported on laparoscopic percutaneous extraperitoneal closure (LPEC) that is now widely applied in inguinal hernia repair in Japan.

They also recommended the performance of LPEC in the treatment of female children with ovarian hernia because the hernia orifice can be closed in a safe and effective manner [12]. However, Ishii et al. reported that simple LPEC for ovarian hernia was associated with a risk of recurrence when sliding of the fallopian tube was present because it led to low ligation and concluded that an additional procedure or conversion to an inguinal approach should be recommended [11].

Over the past years, laparoscopic hernia repair became a wellestablished technique for inguinal hernia in children with good cosmetic outcome. It allows diagnosis of contralateral hernia can be achieved and simultaneous repair [7,13-15]. Recently, there are many other techniques available for application of laparoscope in inguinal 
hernia repair especially in girls as inversion ligation, inversion with cauterization and percutaneous ligation [16-18].

In the present case report, the snare was attached to low cutting diathermy to decease spread of heat to surrounding structure. We proposed that inversion encirclement and snaring of the hernia sac will result in herniotomy with narrow raw area at its neck without much diathermy to surrounding structure.

According to our experience, the advantages of inversion, snaring and peritoneal closure technique are short operative time and adequately remove the whole sac in one mass with no remaining peritoneal bridge that may be the cause of recurrence.

We agreed with other authors that girls are good candidate for new innovative laparoscopic techniques because there is no vas, and vessels passing through the internal inguinal ring. In addition, the majority of young laparoscopic surgeon and resident usually start their training curve with inguinal hernia repair in girls $[19,20]$.

\section{Conclusion}

The technique of needlescopic inversion, encirclement, and snaring of the hernia sac with peritoneal defect closure is reproducible, easy, and promising method for the treatment of inguinal hernia in girls. It resulted in marked reduction of operative time without recurrence.

\section{References}

1. Chang SJ, Chen JYC, Hsu CK, Chuang FC, Yang SSD, et al (2016) The incidence of inguinal hernia and associated risk factors of incarceration in paediatric inguinal hernia: a nation-wide longitudinal population-based study. Hernia 20: 559- Link: 563. Link: https://bit.ly/3fWX9mM

2. Valentina C, Gabriele L, Dacia DR, Nicola P, Pierluigi LC (2013) Irreducible indirect inguinal hernia containing uterus and bilateral adnexa in a premature female infant: report of an exceptional case and review of the literature. J Pediatr Surg 48: e17-e19. Link: https://bit.ly/3fZyrSN

3. Dreuning KMA, Barendsen RW, van Trotsenburg AP, Twisk JWR, Sleeboom C, et al (2020) Inguinal Hernia in Girls: A Retrospective Analysis of Over 1000 Patients. J Pediatr Surg. S00223468(20)30239-6 Link: https://bit.ly/2Vi3xNz

4. Saeki I, Mukai W, Imaji R. Akiyama T (2019) Features and Techniques of Laparoscopic Percutaneous Extraperitoneal Closure for Ovarian Hernia. J Laparoendosc Adv Surg Tech 29: 278-281. Link: https://bit.ly/31gzbPy

5. Turk E, Fescekoglu OR, Acari C, Karaca F, Bilen CM, et al. (2013) Sliding hernias in female children. Acta Chir Belg 113: 281-284. Link: https://bit.ly/3eyAoWa

6. Gaspar MR, Woolley MM, Joergenson EJ (1956) Sliding indirect inguinal hernia. Calif Med 85: 330-334. Link: https://bit.ly/2VfjuEe
7. Shalaby R, Negm M (2020) Laparoscopic Snaring of Hernia Sac for Inguinal Hernia in Girls: A Preliminary Study ASPE 3: 1-5. Link: https://bit.ly/2BF4uZg

8. Houben CH, Chan KW, Mou JW, Tam YH, Lee KH (2015) Irreducible inguinal hernia in children: How serious is it? J Pediatr Surg 50: 1174-1176. Link: https://bit.ly/2VxPNyD

9. Boley SJ, Cahn D, Lauer T, Weinberg G, Kleinhaus S (1991) The irreducible ovary: A true emergency. J Pediatr Surg 26: 1035-1038. Link: https://bit.ly/2BF7pRI

10.El-gohary, Amin M (1997) "Laparoscopic ligation of inguinal hernia in girls." Pediatric Endosurgery \& Innovative Techniques 3: 185188. Link: https://bit.ly/2Vhw7P6

11. Ishii T, Yonekura T, Yamauchi K, Kamiyama M, Morishita $\mathrm{Y}$, et al. (2016) Laparoscopic repair of sliding inguinal hernia in female children. Pediatr Surg Int 32: 895-899. Link: https://bit.ly/37Z8L65

12. Takehara H, Hanaoka J, Arakawa Y (2009) Laparoscopic strategy for inguinal ovarian hernias in children: When to operate for irreducible ovary. J Laparoendosc Adv Surg Tech A 1: S129-S131. Link: https://bit.ly/2Z5oPPL

13.Zallen G, Philip LG (2007) "Laparoscopic inversion and ligation inguinal hernia repair in girls." Journal of Laparoendoscopic \& Advanced Surgical Techniques 17: 143-145. Link: https://bit. ly/383nCwg

14.Yigit SG, Claudia NE, Nikunj KC, Kasper W, Cathy ES (2010) "Inversion herniotomy: a laparoscopic technique for female inguinal hernia repair." Journal of Laparoendoscopic \& Advanced Surgical Techniques 20: 481-484. Link: https://bit.ly/2Z6O7wO

15.Hong-WX, Wen-QD, Qiang-QC, Zhi-HY, Zheng Z, et al. (2015) "Transumbilical single-site laparoscopic inguinal hernia inversion and ligation in girls." Journal of Laparoendoscopic \& Advanced Surgical Techniques 25: 522-525. Link: https://bit.ly/3eHmWzq

16. Ostlie DJ, Todd AP (2014) "Technical options of the laparoscopic pediatric inguinal hernia repair." Journal of Laparoendoscopic \& Advanced Surgical Techniques 24: 194-198. Link: https://bit. ly/387dR03

17.Shalaby R, Ismail M, Dorgham A, Hefny K, Alsaied G, et al. (2010) "Laparoscopic hernia repair in infancy and childhood: evaluation of 2 different techniques." Journal of pediatric surgery 45: 2210-2216. Link: https://bit.ly/3g92eZB

18.Shalaby, Abdalrazek M, Hamed A, Elhady S, Ibrahim R, et al. (2019) Novel application of the sewing machine principle; a new simplified intracorporeal suturing technique for pediatric inguinal. Journal of Pediatric Surgery. 54: 1505-1509. Link: https://bit.ly/386upFx

19.Kantor N, Travis N, Wayne C, Nasr A (2019) Laparoscopic versus open inguinal hernia repair in children: which is the true goldstandard? A systematic review and meta-analysis. Pediatr Surg Int 35: 1013-1026. Link: https://bit.ly/31jACwr

20.Schier F (1998) Laparoscopic Herniorrhaphy in Girls. J Pediatr Surg. 33: 1495-1497. Link: https://bit.ly/31hgdbo 